\title{
The Language of Instruction Dilemma in Ghana: Making a Case for the Various Ghanaian Languages
}

\author{
Ernest Nyamekye, Daniel Baffour-Koduah \\ University of Cape Coast, Department of Arts Education
}

\begin{abstract}
Language plays a significant role in the development of every nation. It mirrors the culture of every society and also reflects the social realities of every nation. It is not surprising, therefore, that every nation goes extra miles in an attempt to keep their languages from sinking. Every nation that gives her culture a priority would therefore put in every effort to develop their native languages. However, there appears to a higher level of reluctance concerning the efforts by concerned stakeholders to promote the indigenous languages of Ghana. This reluctance could be attributed to the prestigiousness attached to the study and use of the English language in the Ghanaian educational system. In light of this, the Ghanaian languages have been despised by many. The common rationale for this despicable attitude towards the local languages is that it has been misconstrued by many stakeholders as unfit for promoting academic excellence. In this paper, however, it is argued, based on research findings, that instruction in the various Ghanaian languages must be given the necessary consideration to accelerate the academic performance of students. To achieve this, the paper recommends that teachers must make complementary use of both English and the Ghanaian languages to facilitate learning at the Junior High Level.
\end{abstract}

Keywords: Ghanaian Languages, Language of Instruction, Language in Education Policy

\section{INTRODUCTION}

$\mathrm{T}$ The role of language in all facets of human life cannot be overemphasised. It provides a voice to culture and acts as a medium that conveys personality and formed ideas from person to person in a speech community (Anani, 2019a). In education, language is considered a significant and inevitable factor since it is the medium through which knowledge is imparted and shared among teachers and students (Lupogo, 2014). It plays an integral role in the teaching and learning process, irrespective of the topic under review. Students successfully integrate new ideas as they listen, speak, read, and write; thus, if the learners' language proficiency is weak, so is their learning (Anani, ibid). Oppong-Sekyere et al. (2013) also corroborate the fact that progress in education depends primarily on language as he points out that success in any type of schooling, training, and practice typically depends on the ability to learn and use language effectively. Dube and Ncube (2013, p. 250), also asserts that "education and language are dependent on each other". Since it is the medium of communication, business, scientific development (Anani, 2019b), the language in education policy of a particular country is, thus considered as a contributing factor to its national development.
Although language cannot be considered the only determinant of successful student learning, the choice of language to be adopted as the instructional medium in most countries (especially multilingual countries) has always sparked fierce debate among educationists and government officials (Kwapong, 2006). As a result, most multilingual societies have devised constitutional clauses that suggest the specific language deemed appropriate for instruction at a specific stage of education. Despite the existence of explicit policies in multilingual societies that suggest the specific language that is deemed appropriate for promoting quality education, there appears to be a lack of implementation strategies (UNESCO 2008).

The inconsistencies regarding language policies in Africa could be attributed to colonial influence. The rationale being that elites in most African countries advocate for strict adherence to the use of foreign languages as the instructional media regardless of the repercussions it places on student learning. As such, Fafunwa (1998) opines that prioritising foreign language as the language of instruction in most African countries is an attribute of colonial mentality. UNESCO (2010) substantiates this assertion as they emphasised that the continuous retention of foreign languages such as French, English and so on, is a result of the pervasive conception that these languages are the most important channels that expose Africans to upward economic mobility and globalisation .One of the major excuses given by various educated elites for pioneering instruction in English only at the basic level of education despite the laid down policy has to do with the multilingual nature of the country (Ansah 2014). However, my stance on this is that this idea of multilingualism in Ghana appears to be a deliberate excuse given as a cover-up for violating the language in Education policy in Ghana. To substantiate this assertion this paper attempts to draw on relevant literature to vindicate my stance that using the English language as the language of instruction at the basic level is a deliberate attempt among most Ghanaian teachers and school heads to portray the prestigious nature of the use English as a means of communication.

\section{A REVIEW OF THE LANGUAGE IN EDUCATION POLICY SITUATION IN GHANA}

During the days of the Christian missionaries, special attention was given to the use of the indigenous languages in the education sector. The Basel missionaries were pioneers in promoting the use of the indigenous languages as instructional 
media and also as subjects of study. Although the Wesleyans did not offer much in promoting the local languages, the Bremen and the Basel mission supported the use of the local languages due to the conception that it is one of the effective means of facilitating teaching and learning among Ghanaian children.

Specifically, one of the prominent and early language policies instituted in the country was the 1925 language policy which was initiated under the governance of Sir Gorden Guggisberg (Wilmot, 2015). Upon the recommendations of the Guggisberg Education Committee which was tasked to review the educational system of the country, the local languages were adopted as media of instruction at the early stages (primary 1-3) of education. English language on the other hand was to be used thereafter. Although this policy was successfully implemented, it was faced with criticisms before, during, and after its implementation. Most educated elites misconstrued it as a calculated effort by the Whitemen to deprive Africans of being exposed to better education. Hence, it was believed that educating the Ghanaian child in his/her language is an attempt to offer an inferior kind of education to $\mathrm{him} / \mathrm{her}$. It is not surprising however that most of the subsequent policies that were instituted by Ghanaian leaders placed overwhelming emphasis on the use of English language as the language of instruction at the detriment of Ghanaian languages for various unsubstantiated reasons.

Under the regime of the Convention Peoples Party (CPP) in the year 1957 when Ghana gained independence from the British colonial rule, a committee was formed to review the language policy. The committee recommended that English only be used as the instructional language in all public schools. The policy was eventually adopted, and thus the use of the local languages as the language of communication in schools was eliminated.

Having identified loop-holes in the aforementioned policy, another committee (the Bannerman Committee) was formed in the year 1963 to resolve the problems of education in the country (Andoh-Kumi, 2002).However, the recommendation of this committee was rejected leading to the institution of the Kwapong Committee which was headed by Professor Kwapong. According to Ankrah (2015), the committee found that teachers were very comfortable with teaching children through their respective indigenous languages. The report of the committee therefore compelled the government to adopt the committee's recommendation. According to Clermont, as cited in Twumasi-Ankrah (2015), the recommendations of the Kwapong's Committee on Ghanaian Language was adopted and emphasized by the Progress Party (PP) that had taken over the administration of the country under the leadership of Dr Busia.

In the year 1970, Ghana reverted to the policy which advocated for the use of local languages in the first three years of primary education. This development led to the establishment of the school of Ghanaian languages in the year
1973. The school aimed at training teachers in various Ghanaian languages to aid a smooth implementation of the policy. The Dzobo committee, in the year 1974, also threw more light on this policy after proposing that every basic school student must learn his/her first language in addition to another Ghanaian language. Among other things too, the committee proposed that the study of the Ghanaian languages be made compulsory from the basic level of education to the university level. (Twumasi-Ankrah, 2015).

In another educational reform initiated in the year 1987, the Provisional National Defence Council (PNDC) reiterated the Dzobo Committee's position that every student should learn any of the Ghanaian languages in addition to his first language. Also, the Ghanaian languages were to be used as the LOI in the first three years of basic education with a gradual transition into English only instruction from primary four.

Several alterations were made to the language in education policy. However, one of the most prominent and recent changes which raised a great debate among educationists in Ghana was the change initiated by the NPP government in the year 2002. This policy abolished the use of Ghanaian languages as the LOI. The rationale for the abolishment of the use of the Ghanaian languages was that teachers, especially those in the rural areas were abusing the use of Ghanaian languages as the LOI at the detriment of the English language. The government's decision to abolish the Ghanaian languages, according to Professor Ameyaw-Akumfi, the then Minister of Education, was informed by the realisation that the English proficiency of the students was being compromised. Thus, according to the minister of education, students were unable to construct good English sentences which in turn impedes their academic progress. Ansah (2014), asserts that this decision by the government to abolish the use of Ghanaian languages was backed by the consent of parents. This, therefore, sheds more light on the fact that the use of Ghanaian languages has been despised by parents, educationists, and government officials due to the prevailing misconception that it does not accelerate literacy. This policy was eventually reversed in 2007 when it was faced with lots of criticisms by different educationists and interest groups. Table 1 gives a historical overview of the Ghanaian language in education policy implementation.

Table 1: Historical overview of Ghanaian Language in Education Policy Implementation

\begin{tabular}{|c|c|c|c|c|c|}
\hline Period & & P1 & P2 & P3 & P4-JHS \\
\hline $1529-1925$ & $\begin{array}{c}\text { Castle Schools Era } \\
\text { Missionary Era }\end{array}$ & $\begin{array}{c}- \\
+\end{array}$ & $\begin{array}{c}- \\
+\end{array}$ & $\begin{array}{c}- \\
+\end{array}$ & - \\
\hline $1925-1951$ & & + & + & + & - \\
\hline $1951-1955$ & & + & - & - & - \\
\hline $1956-1966$ & & - & - & - & - \\
\hline $1967-1969$ & & + & - & - & - \\
\hline $1970-1973$ & & + & + & + & + \\
\hline
\end{tabular}




\begin{tabular}{|c|c|c|c|c|c|}
\hline $1974-2002$ & & + & + & + & + \\
\hline $2002-2007$ & & - & - & - & - \\
\hline 2007 to date & & + & + & + & - \\
\hline
\end{tabular}

Source: Adapted from (Owu-Ewie, 2006)

Key: $+=$ Ghanaian language was used as the language of instruction

$=$ Ghanaian Language was not used

Despite these numerous changes to the language in education policy over the years, Ghana is currently on the Language in Education Policy which advocates for the use of local languages at the lower level of primary education (P1 - P3) and English Medium from Primary 4 upwards. This Policy was further emphasised by the National Accelerated Literacy Program. In 2006, the National Accelerated Literacy Programme (NALAP) was introduced. It was developed by National Literacy Task Force (NLTF) which was set up by the Ghana Education Service (GES) to investigate the low literacy skills identified as the major factor undermining quality education (Anyidoho, 2018). "The task force recommended the adoption of the National Literacy Acceleration Programme (NALAP), an instructional approach which provides teachers and pupils of the Lower Primary level (KG 1 - P3) with quality literacy materials, effective instruction, and public support to read and write in their local language and English. The methodology seeks to make pupils literate in their local language for a smooth transition to English. Therefore, by P3, it is expected that the pupils would be fully bilingual" (GES REPORT, 2010, P.1). The rationale for the introduction of this policy was "...to equip the majority of children leaving the basic education system with skills of literacy that would improve their learning abilities and serve as a springboard for further academic pursuit. This means that by P3, pupils would be functionally literate and would achieve reading fluency in their local language (L1) and in English (L2)" (GES report, 2010:1).

According to Ansah (2015), table 1 below is the proposed implementation plan for the Language in Education policy. It clearly shows the English and Ghanaian Language ratio for the implementation.

Table 2: NALAP Implementation Plan

\begin{tabular}{|c|c|c|}
\hline Level & $\begin{array}{c}\text { Ghanaian } \\
\text { Languages }\end{array}$ & English Language \\
\hline $\begin{array}{c}\text { Kindergarten 1 and } \\
2\end{array}$ & $90 \%$ & $10 \%$ \\
\hline Primary 1 & $80 \%$ & $20 \%$ \\
\hline Primary 2 - 4 & $50 \%$ & $50 \%$ \\
\hline Primary 4- JHS & $0 \%$ & $100 \%$ \\
\hline
\end{tabular}

Source: Ansah, (2015)

III. A REVIEW OF RESEARCH FINDINGS ON THE USE OF GHANAIAN LANGUAGES AS THE LANGUAGE OF INSTRUCTION
Issues concerning the use of the child's first language as the instructional medium remains a contest in literature. While most research advocates for instruction in local languages due to its significant academic impact, other studies points accusing fingers on local languages for being one of the major causes of student's poor academic performance in various subject areas. For instance, Etsey (2005) conducted a causalcomparative study that sought to explore the causes of low academic performance of primary school pupils in the Shama Sub-Metro of Shama Ahanta East Metropolitan Assembly (SAEMA) with a sample of 495 pupils, 25 head teachers, 133 teachers, and 581 parents. Among other issues, the study found that the use of the local languages among students and as the LOI in the classroom was one of the major causes of the students' low academic performance in the SAEMA. He pointed out that high achieving schools were the schools that used the English language as a medium of communication in and outside the classroom. The reason attached to the finding was that the textbooks that are used by the pupils are written in English and in cases where the local language is used as a medium of instruction, it creates deficiencies in student's understanding which consequently results in low academic performance. However, the findings of this study could be contested on the grounds that in the case of the high achieving schools, teachers reported that students had access to the requisite teaching and learning materials, had parental assistance with home works, had the necessary parental support, and also teachers were enthusiastic towards the teaching profession. Furthermore, it was highlighted that in low achieving school, students were deprived of certain fundamental academic support from both parents and the government. Hence it would be erroneous to blame the use of the local languages for low academic standard without considering other variables that come to play.

Also, Amua-Sekyi and Nti (2015), conducted a qualitative study that employed classroom observations, interviews, and focus group discussions with students and teachers to examine the factors affecting students' performance in English at colleges of education in Ghana. This study, like that of Etsey (ibid), found that the low academic standards of students in the English language was due to the use of the local languages as the communicative medium among teachers and students, and also as an instructional language. It was therefore recommended that English be used as the language of communication among teachers and students be made mandatory. It would be very reasonable to accept the findings and recommendations of Amua-Sekyi and Nti (ibid), Etsey (ibid), on the grounds that the English language is the language of the curriculum in Ghana, and thus instruction in it would arguably promote learning. However, it should be noted, as asserted by Cummins (2008), that to use a foreign language as the sole instructional language, one must develop the Cognitive Academic Language Proficiency (CALP) which goes beyond the mere ability to recognise and decode foreign language sentences. It could therefore be contested that making instruction in English language mandatory would be a 
danger to student learning since most students and teachers lack this language proficiency. To substantiate this, a study by Opoku-Amankwa (2009) which examined the influence of the English-only language in education policy on pupils' classroom communicative practices, confirms the fact that using English language as the sole LOI impedes the academic progress of the pupils. His observations conducted in the classroom revealed that English only as LOI breeds language anxiety and low self-esteem. It is therefore important to note that any LOI other than the pupils' mother tongue which is familiar to the pupils can affect the comprehension of the pupils to a large extent as revealed by these studies. Correspondingly, Fredua-Kwarteng and Ahia, (2015) conducted a study that sought to ascertain how English only instruction could affect the teaching and learning of mathematics. They concluded that studying mathematics through the English language could impede the growth of mathematics skills among students. Students were found facing immense difficulties in communicating their perspectives on mathematics topics in English. Additionally, they found it very difficult in applying their daily mathematics practices they engage in at their respective communities into the classroom setting due to this language barrier caused by their inability to articulate in the English language.

In an attempt to unearth the benefits of using the child's first language as the LOI, Wilmot's (2003) study revealed that using a familiar language rather facilitates teaching and learning. His observation in the classroom revealed that a student considered to be 'fairly average' by his teacher was able to solve mathematical problems correctly but was unable to give further account on how he arrived at the answer. However, when asked to explain it in his mother tongue (Ewe), he was able to explain it perfectly and also demonstrated competency in abstract thinking contrary to when he was forced to explain in English. He further noticed that the student who has been considered to be 'fairly average' by his teacher was equally good as those who were considered as 'above average'. However, the difference that existed between them was proficiency in the LOI. Similarly, NgmanWara, (2005) examined the "influence of local languages on Ghanaian Junior Secondary School students' understanding of some science concepts. A sample of 1028 students from 12 Junior Secondary Schools in the Northern region participated in pre-test and post-test multiple-choice tests. The tests first sought to find out the extent to which the students understand science concepts and secondly to find out how their native language influenced this understanding. The study found that students performed better on 'science concepts with native language equivalent words' than those without 'native language equivalent words' with percentage mean scores of $32.2 \%$ and $29.1 \%$ respectively. The study, therefore, concluded that the native language of the learner has an influence on their understanding of science concepts and thus, the role of the native language of the student in the delivery of science lessons cannot be ignored. With a quasi-experimental design, Kwapong (2006), also conducted a similar study that compared the impact of the use of local language (L1) and English (L2) on pupils' performance in mathematics at the lower primary level. The research, which was undertaken in the Suhum Kraboa Coaltar District of the eastern region of Ghana, adopted a quasi-experimental style. In this study, two schools (one in an urban and the other in a rural area) were purposively selected for the study. The results of the test indicated no significant difference between the English medium of instruction and the local language medium of instruction. However, it was found that the use of the English language benefits urban schools rather than the use of the local language, while in rural schools the local language is more effective for teaching mathematics at a lower primary level than English (L2). It was also found that the use of L1 increases the performance of pupils in problem-solving rather than the use of English. It was therefore recommended that the language choice in teaching mathematics should be left for the staff of a given school to decide.

In a more recent study that aimed at exploring the significance of adopting the NALAP which emphasized the use of the child's first language as the LOI in the Northern region in Ghana, Abreh and Wilmot (2018), revealed that using the child first language as the language of instruction facilitated learning.

\section{CONCLUSION AND RECOMMENDATIONS}

Based on the research findings reviewed in this paper, it could be concluded that adopting the English language as the sole LOI at the Basic and Junior High School level rather impedes the academic progress of students, especially in schools where the English proficiency of teachers and students falls below the expected standards. This, therefore, throws more light on the significance of using the various Ghanaian languages as the LOI in teaching and learning as it creates an enabling environment for students to participate effectively in teaching and learning. I, therefore, believe that using the local languages in teaching and learning is the best medium of educating the Ghanaian child.

Nonetheless, in light of these contradictory research findings on the use of the local languages as the instructional media, teachers are therefore left in a dilemma concerning which language to adopt. This situation continues to maintain two different sets of beliefs about the use of the local languages as LOI. As some teachers subscribe to the belief that using Ghanaian language facilitates teaching and learning, others stick to English only instruction with the belief that exposing students to English only instruction at the early stages of education would give them a head start in climbing up the academic ladder. This two different set of conceptions among teachers is the reason why there has not been stability with respect to the language in education policy implementation.

To deal with this situation, however, I offer three recommendations that policymakers could consider. 
1. Given the important role of the local languages in accelerating learning, it is recommended that stakeholders should offer clear guidelines to follow in the implementation of the local language medium of instruction. Also, other factors such as the provision of adequate teaching and learning material that would aid the smooth running of the policy should be addressed.

2. Also, there must be a scrutiny of the placement criteria of trained teachers to various schools. The rationale is that most of the teachers are placed in schools where they have limited knowledge in the local language of the people. This, therefore, creates a language barrier between the teachers and students.

3. Finally, teachers, in the course of implementing the local language instruction policy, must also put in place effective measures to enforce the acquisition of English. By doing this, pupils would be linguistically prepared as they gradually transit into English-only medium of instruction at primary four.

\section{REFERENCES}

[1]. Abreh, M. K., \& Wilmot, E. M. (2018). Implementing National Accelerated Language Programme (NALAP) in Northern Ghana: Lessons from the Wing Schools. African Journal of Educational Studies in Mathematics and Sciences, 14, 101-114.

[2]. Etsey, K. (2005). Causes of low academic performance of primary school pupils in the Shama Sub-Metro of Shama Ahanta East Metropolitan Assembly (SAEMA) in Ghana. A paper presented at the regional conference on education in West Africa, Dakar, Senegal

[3]. Amua-Sekyi, E. T., \& Nti, S. K. (2015). Factors Affecting Students' Performance in English at Colleges of Education in Ghana. International Journal of Research in Humanities, Arts and Literature, 3(10), 29-44.

[4]. Anani, G. E (2019a). Taking a Stance on the Language in Education Policy and Planning in Ghana: Concept Paper. International Journal of Research and Innovation in Social Science (IJRISS) 40-43

[5]. Anani, G.E (2019b) A Review of Existing Debates That Have Persisted Over the Choice of Language as a Medium of Instruction in Ghanaian Classrooms. International Research in Education. 7(2), 38-43

[6]. Andoh-Kumi, K. (2002). Language of instruction in Ghana (Theory, Research, and Practice). Legon: Language Centre, University of Ghana-Legon, IEQ-Ghana

[7]. Ansah, G.N. (2014), Re-examining the fluctuations in language ineducation policies in post-independence Ghana. Multiling.Ed.4, $12 \mathrm{https} / / /$ doi.org/10.1186/s13616-014- 0012-3

[8]. Ansah, M. A., \& Agyeman, N. A. (2015). Ghana language-ineducation policy: The survival of two South Guan minority dialects. Per Linguam: a Journal of Language Learning per Linguam: Tydskrif vir Taalaanleer, 31(1), 89-104.

[9]. Anyidoho, A. (2018). Shifting Sands: Language Policies in Education in Ghana and Implementation Challenges. Ghana Journal of Linguistics, 7(2), 225-243.

[10]. Cummins, J. (2008). BICS and CALP: Empirical and theoretical status of the distinction. Encyclopedia of language and education, 2(2), 71-83.

[11]. Etsey, K. (2005). Causes of low academic performance of primary school pupils in the Shama Sub-Metro of Shama Ahanta East Metropolitan Assembly SAEMA) in Ghana. In Proceedings of the Regional Conference on Education in West Africa.
[12]. Dube, L., \& Ncube, B. (2013). Language policy and linguistic rights in post-colonial Zimbabwe: The case of IsiNdebele. Greener Journal of Social Sciences, 3(5), 249-255.

[13]. Fafunwa, A. B. (1998). Sense and Nonsense in Nigerian Education. Nigerian National Merit Award Winner's Lecture, Abuja, Umanity International Co. Ltd.

[14]. Fredua-Kwarteng, E., \& Ahia, F. (2015). Learning Mathematics in English at Basic Schools in Ghana: A Benefit or Hindrance?. European Journal of Educational Research,4(3), 124-139

[15]. Kwapong, J. O. (2006). Effects of using english and local language on the study of mathematics at the lower primary in the Suhum Kraboa Coalter district of Ghana (Masters thesis, University of Cape Coast).

[16]. Lupogo, I. (2014). Language of Instruction: A Challenge for Secondary Schools and Tertiary Institutions in Implementing VET in Tanzania. Journal of Educational Policy and EntreResearch, 1(3), 26-30.

[17]. Opoku-Amankwa, K. (2009). English-only language-in-education policy in multilingual classrooms in Ghana. Language, Culture and Curriculum, 22(2), 121-135.

[18]. Oppong-Sekyere, D., Oppong-Sekyere, F., \& Akpalu, M. M. (2013). Some $\mathrm{f}$ actors influencing the academic performance of junior high school pupils in English Language: The case of Assin North Municipality, Ghana. International Journal of English and Literature, 4(5), 226-235.

[19]. Twumasi-Ankrah, O. (2015). Education experts' perceptions of the Ghanaian language policy and its implementation. Acta Universitatis Lapponiensis 308. Rovaniemi: University of Lapland

[20]. UNESCO (2010). Why and how Africa should invest in African languages and multilingual education. An evidence- and practice-based policy advocacy brief. Germany: UNESCO Institute of Lifelong Learning

[21]. UNESCO. (2008a) First Meeting of the Working Group of IBC and First Public Hearings on Human Cloning and International Governance. Paris, France.

[22]. Ngman-Wara, E. (2005). The Influence of 8ative Language on Ghanaian Junior Secondary School Studentsl'Understanding of some Science Concepts. African Journal of Educational Studies in Mathematics and Sciences, 3, 43-52.

[23]. Wilmot, E. M. (2003, March). Stepping outside the ordinary expectations of schooling: Effect of school language on the assessment of educational achievement in Ghana. In 47th Annual Meeting of CIES March (pp. 12-16).

[24]. Wilmot, K. (2015). Providing'auxiliary'academic writing support to postgraduate students: a socio-cultural approach. Journal for Language Teaching = Ijenali Yekufundzisa Lulwimi= Tydskrif vir Taalonderrig, 49(2), 129-147. 